\title{
Chinese Herbal Medicine YQ1
}

National Cancer Institute

\section{Source}

National Cancer Institute. Chinese Herbal Medicine YQ1. NCI Thesaurus. Code C136984.

A Chinese herbal medicine, with potential immunostimulating and antineoplastic activities.

Although the mechanism of action is currently unknown, upon administration, YQ1 may cause an induction of apoptosis and an inhibition of tumor cell proliferation. YQ1 might target cancer stem cells (CSCs). 